\title{
Progress in Antitumor Activity of Diterpenoid Alkaloids
}

\author{
Xiao-Jing Shen, ${ }^{a, b, c}$ Ting-Ting Zheng, ${ }^{d, e}$ Hong Wang, ${ }^{a}$ Jiao Cai, ${ }^{a}$ Cheng-Ting $\mathrm{Zi}^{\star, a}$ and Jiang-Ping Fan ${ }^{\star, c}$ \\ ${ }^{a}$ College of Science, Yunnan Agricultural University, Kunming, Yunnan 650201, China \\ ${ }^{b}$ Yunnan Key Laboratory of Pharmacology for Natural Products, Kunming Medical University, \\ Kunming, Yunnan 650500, China \\ ${ }^{c}$ College of Food Science and Technology, Yunnan Agricultural University, Kunming, Yunnan 650201, China \\ ${ }^{d}$ College of Tea (Pu' er), West Yunnan University of Applied Sciences, Pu'er, Yunnan 665000, China \\ ${ }^{e}$ Pu'er Institute of Pu-erh Tea, Pu'er, Yunnan 665000, China \\ Email: zichengting@126.com (C. Z.), 1993033@ynau.edu.cn (J. F.)
}

\begin{abstract}
Diterpenoid alkaloids are a diverse group of natural products with significant structural complexity and bioactivities, including anti-inflammatory, anti-arrhythmia, analgesia, local anesthetic, muscle relaxant, hypotensive, anti-tumor and immune regulation. In this article, we summarized the progress in antitumor activity of diterpenoid alkaloids to provide ideas for medicinal development prospects of antitumor.
\end{abstract}

Keywords diterpenoid alkaloids, antitumor activity, progress

\section{Introductions}

Diterpenoid alkaloids (DAs) are a diverse group of natural products with significant structural complexity and bioactivities, as well as infamous toxicity. According to the references, DAs are mainly characteristic in Ranunculaceae species, especially the genera Aconitum, Delphinium and Consolida. ${ }^{[1]}$ The pharmacological properties of DAs include anti-inflammatory, ${ }^{[2]}$ anti-arrhythmia, ${ }^{[3]}$ analgesic, ${ }^{[4]}$ anti-tumor, ${ }^{[5]}$ immune regulation, ${ }^{[6]}$ antioxidant and anticholinesterase activities. ${ }^{[7]}$ DAs were usually divided into four categories, $\mathrm{C}_{18^{-}}, \mathrm{C}_{19^{-}}, \mathrm{C}_{20^{-}}$and bis-DAs according to categories.

Akhtar et al. ${ }^{[8]}$ pointed out that most of natural DAs with anticancer effects in Aconitum were $\mathrm{C}_{19}$-DAs and derivatives of $\mathrm{C}_{20}$-DAs had also notable anticancer potential. At the same time, the activity of DAs were improved by simple structural modification. Ren et al ${ }^{[9]}$ had reviewed one $\mathrm{C}_{18}$-DAs (Lappaconitine), twelve $\mathrm{C}_{19}$-DAs (Lycaconitine, aconitine, oxonitine, deoxyaconitine, $\quad(1 \alpha, 6 \alpha, 8 \alpha, 14 \alpha, 16 \alpha)$-20-ethyl-8,14-dihydroxy1,6,16-trimethoxy-4-(methoxymethyl)-aconitane, mesaconitine, crassicauline A, 8-O-azeloyl-14-benzoylaconine, 14-O-acetylneoline, neoline, hypaconitine and cammaconine) and 33 natural and synthesized $\mathrm{C}_{20}$-DAs (12-epi-napelline, songorine, atisinium chloride, pseudokobusine, 11,15-dianisoylkobusine, 12-acetylluciculine, 6,11-dibenzoylpseudokobusine, 11-veratroylpseudokobusine, 11-cinnamoylpseudokobusine, 11-anisoylpseudokobusine, etc.) with antitumor activities. Wada et al. ${ }^{[10]}$ also summarized 200 natural and semi-synthetic DAs against human tumor cells. They found that $\mathrm{C}_{19}$-DAs and $\mathrm{C}_{20}$-DAs exhibited significant cytotoxic activity and several DAs were more potent against MDR subline KB-VIN cells than the parental drug-sensitive KB cells.

In this paper, we summarized the progress in unreviewed antitumor activity of different categories of DAs in recent years to provide a reference for better utilization of DAs and development of antitumor medicines.

\section{Antitumor Activity of $\mathrm{C}_{18}$-Diterpenoid Alkaloids}

$\mathrm{C}_{18}$-DAs, as a small group with the DAs, originated from

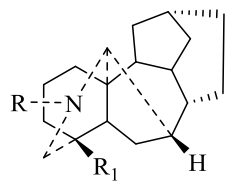

lappaconitine type



puberunine type

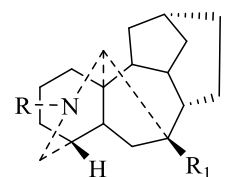

ranaonitine type

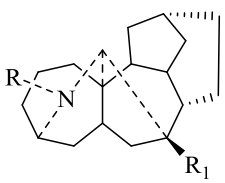

sinomontadine type

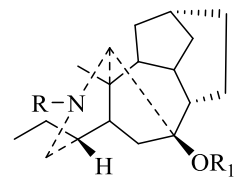

puberudine type
Figure 1 Types of $\mathrm{C}_{18}$-diterpenoid alkaloids.

$\mathrm{C}_{19}$-DAs by losing one carbon at $\mathrm{C}-18$, which include applaconitine, ranaonitine and rearranged types. ${ }^{[1]}$ Their classes are shown in Figure 1. Lappaconitine could inhibit proliferation of human non-small cell lung cancer cells A549. ${ }^{[11]}$ Lappaconite hydrobromide, as a derivative of lappaconitine, exerted an efficient antitumor effect in mice with inhibition rates ranging from $11.20 \%$ to $53.08 \%$ for liver tumor growth and $29.81 \%$ to $53.96 \%$ for S180 tumor growth. ${ }^{[12]}$

\section{Antitumor Activity of $\mathrm{C}_{19}$-Diterpenoid Alkaloids}

$\mathrm{C}_{19}$-DAs are the largest group among DAs with six types including aconitine, lycoctonine, lactone, 7,17-seco, franchetine and rearranged types (Figure 2). ${ }^{[1]}$

Nagaconitine $\mathrm{C}$ (1), a new $\mathrm{C}_{19}$-diterpenoid alkaloid from Aconitum nagarum var. heterotrichum, inhibited cancer cell line SK-OV-3 with $31 \%$ in vitro and $\mathrm{IC}_{50}$ value was $43.78 \mu \mathrm{mol} / \mathrm{L}^{[13]}$ Delsemine A (2) exhibited slight activity at $100 \mu \mathrm{M}$ against human breast cancer cell lines of MDA-MB-231 MCF-7, but it did not reach the $\mathrm{EC}_{50} \cdot{ }^{[14]}$ Sinchiangensine $A(3)$ and lipodeoxyaconitine (4) were firstly isolated from Aconitum sinchiangense with significant antitumor activities against tumour cells (HL-60, A-549, SMCC-7721, MCF-7 and SW480). ${ }^{[15]}$ 

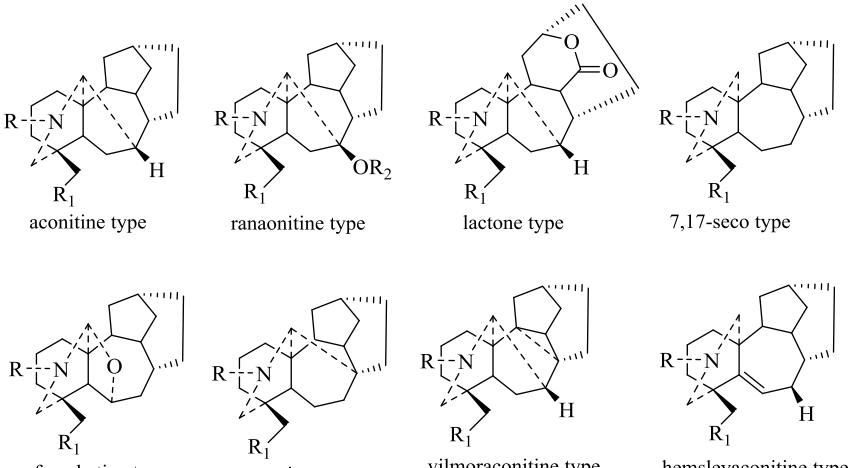

franchetine type acoseptine type
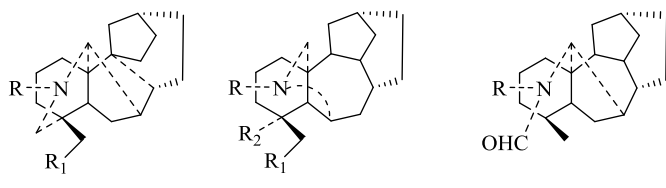

vilmotemnitine type

franchetine type

$N$-formyl-4,19-secopacinine type

Figure 2 Types of $\mathrm{C}_{19}$-diterpenoid alkaloids.

\section{Antitumor Activity of $\mathrm{C}_{20}$-Diterpenoid Alkaloids}

The skeleton of $\mathrm{C}_{20}$-DAs consists of 20 carbons, which is likely the precursor of $\mathrm{C}_{18^{-}}$and $\mathrm{C}_{19}$-DAs. Twenty-three DAs classes have been identified (Figure 3 ). ${ }^{[1]}$ The isolated $\mathrm{C}_{20}$-DAs are mainly atisine-, hetisine-, and napelline-types and include atisine, kobusine, pseudokobusine and lucidusculine. ${ }^{[11]}$

Nagaconitine D (5), a new $\mathrm{C}_{20}$-diterpenoid alkaloid from Aconitum nagarum var. heterotrichum, could also inhibit cancer cell lines SK-OV-3 with $24 \%$ in vitro and $\mathrm{IC}_{50}$ value was 32.14 $\mu \mathrm{mol} / \mathrm{L}^{[13]}$

Wada et al. ${ }^{[16]}$ studied the structure-activity relationship of $\mathrm{C}_{20}$-diterpenoid atisine-type alkaloid with cytotoxic activity against A549 human lung carcinoma cells. The results showed that benzoyl and benzyl substitutions were inactive; cinnamoyl, $p$-nitrobenzoyl, $m$-trifluoromethylbenzoyl and veratroyl substitutions were effective. Moreover, anisoate was about 2 -fold more potent than substrates. They concluded that C-6 and $\mathrm{C}-15$ hydroxyl groups in pseudokobusine were necessary for a cytotoxic effect and esterification of the hydroxyl group at C-11 might contribute more to enhancement of activity of parent alkaloids than that of the $\mathrm{OH}$ group at $\mathrm{C}-11$.

Furthermore, the replacement by an acyl group at C-15 in 11-substrates was involved in activation of cytotoxic effects. They also reported that acylated alkaloid derivatives could inhibit cell growth through G1 arrest.

\section{Antitumor Activity of Bis-diterpenoid Alkaloids}

A bis-DAs, navicularine $B(6)$, was isolated from the ground parts of Aconitum naviculare possessing certain cytotoxic

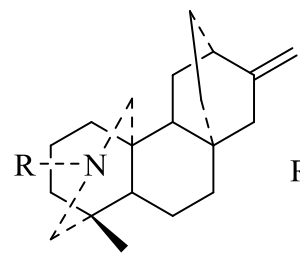

atisine type

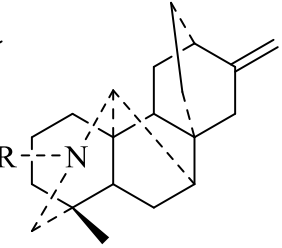

denudatine type

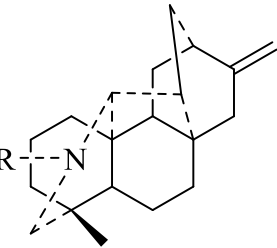

hetidine type

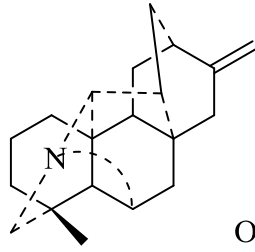

hetisine type

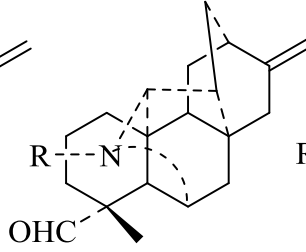

vakognavine type

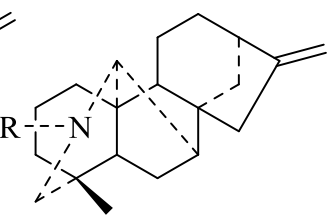

napelline type

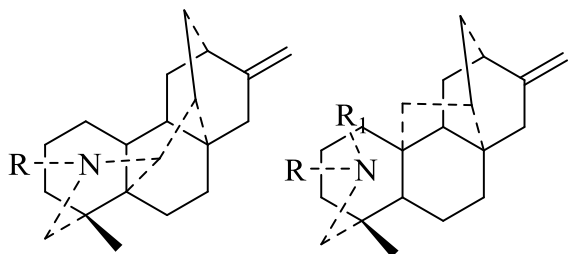

arcutine type

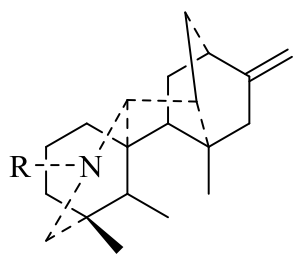

cardionidine type



spireine type

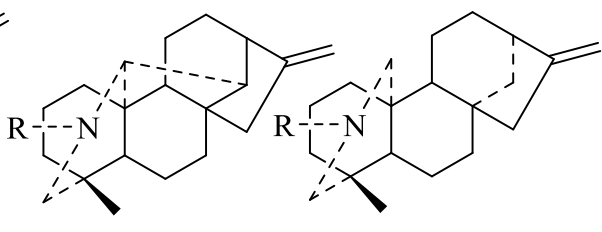
anopterine type veachine type

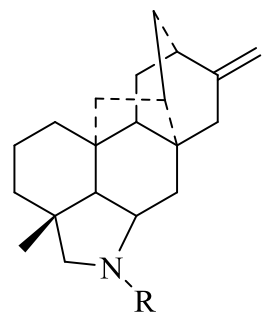

grandiflodine type

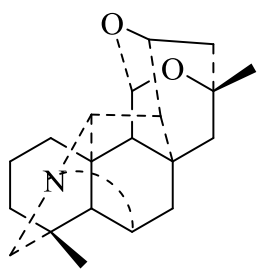

kusnezoline type

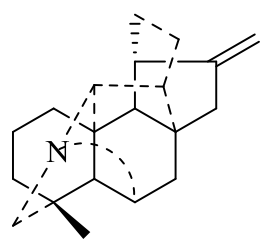

delnudine type

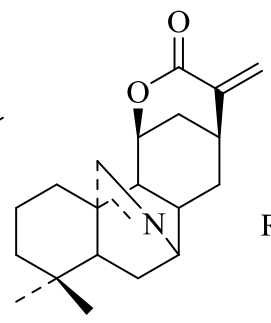

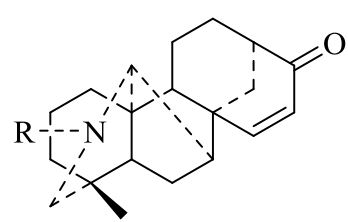

kaurine A type aconicarmisulfonine type

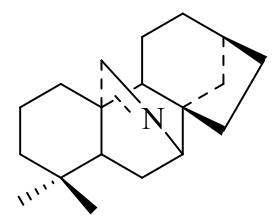

kaurine B type<smiles>[R]N1CCC2C1CC[C@@]1(C)C2CCC23CC(=C)C(CCC21)C3</smiles>

tricalysiamide type



caesanine type

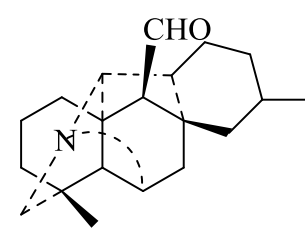

anthriscifolsine type

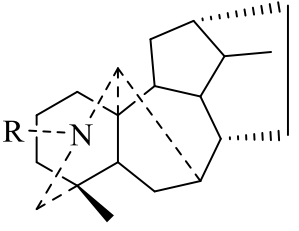

actaline type

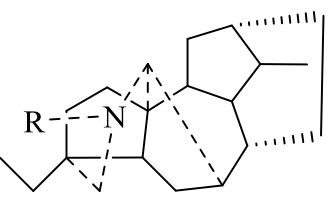

racemulosine type

Figure 3 Types of $\mathrm{C}_{20}$-diterpenoid alkaloids. 

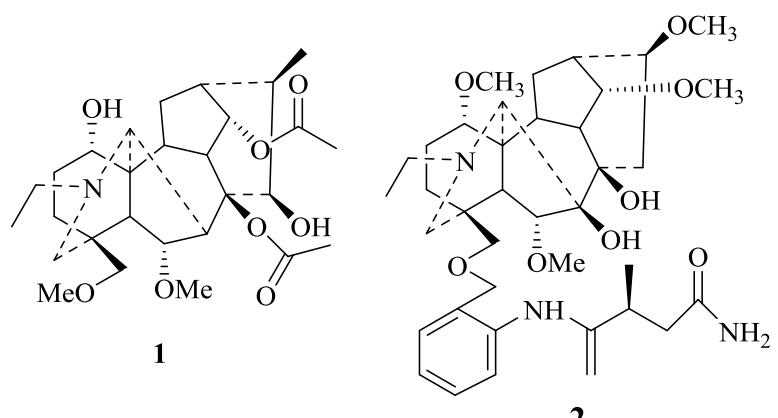



3

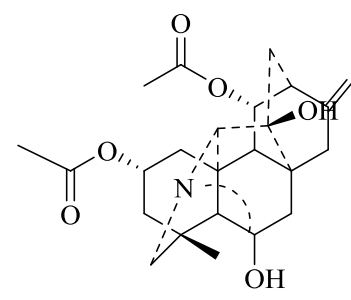



4

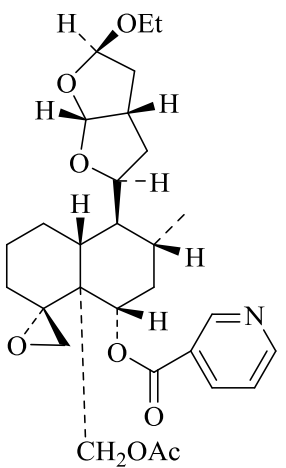

7<smiles>CC1=CCCC2[C@]3(C)O[C@]4(COC(=O)C4)C[C@H](OC(=O)c4cccnc4)[C@@]3(I)[C@H](OC(=O)c3cccnc3)[C@@]12C</smiles>

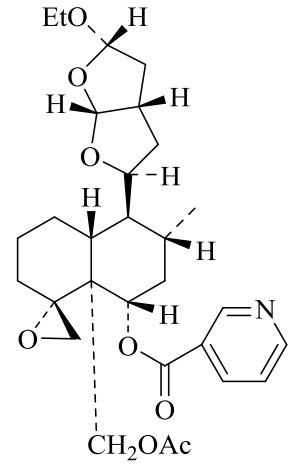

8

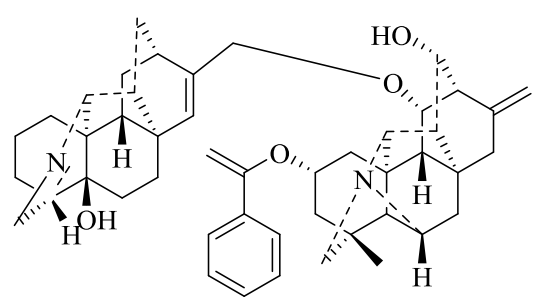

6

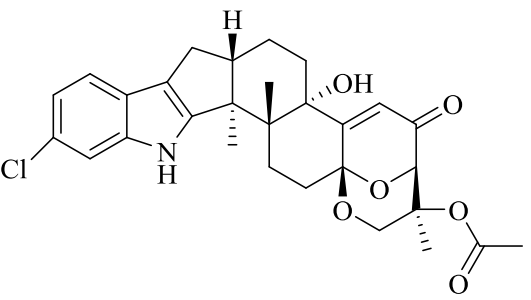

16

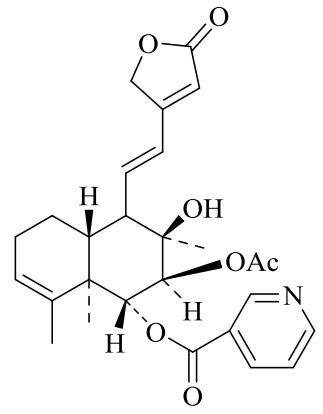

9



10



11

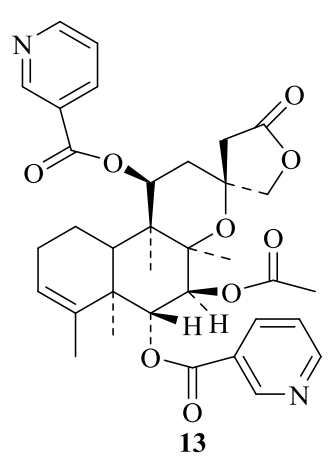





15

Figure 4 The structures of compounds $1-16$.

activities against five cell lines (HL-60, SMMC-7721, A549, MCF-7, SW480) in vitro with $\mathrm{IC}_{50}$ values of $13.50,18.52,17.22$, 11.18 , and $16.36 \mu \mathrm{M}$, respectively (Figure 4). ${ }^{[7]}$

Antitumor Activity of Other Classes Diterpenoid Alkaloids

Nine new neo-clerodane DAs, scutebarbatines $\mathrm{L}-\mathrm{L}(\mathbf{7}-\mathbf{1 0})$, scutebarbatine $\mathrm{G}$ (11), 6,7-di-O-nicotinoylscutebarbatine $\mathrm{G}$ (12), 6-O-nicotinoyl-7-O-acetylscutebarbatine $\mathrm{G}$ (13), scutebarbatine $\mathrm{H}$ (14) and 7-O-nicotinoylscutebarbatine $\mathrm{H}$ (15) were isolated from Scutellaria barbata D. DON. According to the bioassay against three human cancer lines in vitro, 7-15 showed significant cytotoxic activities and $\mathrm{IC}_{50}$ values were in the range of 3.2-8.3 $\mu \mathrm{M}$ (Table 1). ${ }^{[18,19]}$ Asperindole A (16), an indole-DA, was proved to be highly cytotoxic in $22 \mathrm{Rv} 1$ human prostate cancer cells with $\mathrm{IC}_{50}$ values of $4.86 \mu \mathrm{M}^{[20]}$
Table $1 \quad \mathrm{IC}_{50}$ values of compounds $7-\mathbf{1 5}$

\begin{tabular}{cccc}
\hline \multirow{2}{*}{ No. } & \multicolumn{3}{c}{$\mathrm{IC}_{50} / \mu \mathrm{M}$} \\
\cline { 2 - 4 } & $\mathrm{HONE}-1$ & $\mathrm{~KB}$ & $\mathrm{HT} 29$ \\
\hline $\mathbf{7}$ & $4.2 \pm 2.2$ & $4.7 \pm 2.7$ & $7.5 \pm 2.6$ \\
$\mathbf{8}$ & $4.4 \pm 1.9$ & $5.1 \pm 1.8$, & $8.3 \pm 1.1$ \\
$\mathbf{9}$ & $3.9 \pm 2.2$ & $5.5 \pm 2.0$ & $5.9 \pm 2.7$ \\
$\mathbf{1 0}$ & $3.2 \pm 2.3$ & $5.6 \pm 1.3$ & $6.0 \pm 1.5$ \\
$\mathbf{1 1}$ & $3.7 \pm 2.0$ & $7.1 \pm 2.2$ & $6.9 \pm 1.3$ \\
$\mathbf{1 2}$ & $5.0 \pm 3.2$ & $8.5 \pm 1.7$ & $6.6 \pm 2.4$ \\
$\mathbf{1 3}$ & $4.5 \pm 1.5$ & $6.1 \pm 2.6$ & $5.3 \pm 2.0$ \\
$\mathbf{1 4}$ & $4.4 \pm 2.7$ & $6.1 \pm 2.2$ & $3.5 \pm 3.4$ \\
$\mathbf{1 5}$ & $3.7 \pm 2.0$ & $6.7 \pm 2.6$ & $3.4 \pm 2.1$ \\
\hline
\end{tabular}

\section{Antitumor Mechanism of Diterpenoid Alkaloids}

Taipeinine A had anticancer effects on human HCC cell line 
(HepG2) and could inhibit proliferation of HepG2 cells in a dose- and time-dependent manner, block cell cycle at G1/S phase, inhibit invasiveness of HepG2 cells and induce significant apoptosis of tumor cells at high dosage. Zhang et al. ${ }^{[21]}$ presumed antitumor mechanism of taipeinine $A$ at molecular level was upregulating the protein expression of Bax and Caspase-3 and downregulating protein expression of $\mathrm{Bcl}-2$ and CCND1.

\section{Conclusions and Perspective}

DAs have strong bioactivity and wide sources. $\mathrm{C}_{19}$ and $\mathrm{C}_{20}$-DAs are main inhibitors of tumor cells. In addition, it is not difficult to find many DAs with better viability by simple structural modification. However, the current studies on the antitumor activities of DAs are mainly focused on in vitro (few in vivo and clinic); moreover, the structure-activity of DAs was completely unambiguous. At the same time, the studies on mechanism and pharmacokinetics of antitumor DAs were rare. Thus, a series of semi-synthetic DAs derivatives were synthesized by modification through oxidation, acylation, ether formation and rearrangement using DAs as substrates. In the future, researchers are expected to continue to find new diterpene alkaloids with antitumor activities and synthesize ADs derivatives with high efficacy, low toxicity by structural modification and structure-activity relationship research to provide a theoretical basis for clinical safe drug and further development of new antitumor drugs. DAs, as significantly potential antitumor compounds, will provide promising new lead compounds for further development as antitumor agents.

\section{Acknowledgment}

This work was financially supported by grants from the National Nature Science Foundation of China (No. 31960075), the Yunnan Provincial Education Department Program (No. 2020J0241), and the University Students Innovation Training Project of Yunnan Province (No. 202010676037).

\section{Conflict of Interest}

The authors declare no conflict of interest.

Copyright $(92020$ XiaoJing Shen, Tingting Zheng, Hong Wang, Jiao Cai, Chengting $\mathrm{Zi}$, and Jiangping Fan. This article is an open access article distributed under the terms and conditions of the Creative Commons Attribution (CC BY) license (http://creativecommons.org/licenses/by/ 4.0/). The use, distribution or reproduction in other forums is permitted, provided the original author(s) or licensor are credited and that the original publication in this journal is cited, in accordance with accepted academic practice. No use, distribution or reproduction is permitted which does not comply with these terms.

\section{References}

[1] Shen, Y.; Liang, W. J.; Shi, Y. N.; Kennelly, E. J. Structural diversity, bioactivities, and biosynthesis of natural diterpenoid alkaloids. Nat. Prod. Rep. 2020, 37, 763-796.

[2] Yin, T. P.; Hu, X. F.; Mei, R. F.; Su, Y.; Gan, D.; Cai, L.; Ding, Z. T. Four new diterpenoid alkaloids with anti-inflammatory activities from Aconitum taronense Fletcher et Lauener. Phytochem. Lett. 2018, 25, 152-155.

[3] Kiss, T.; Borcsa, B.; Orvos, P.; Talosi, L.; Hohmann, J.; Csupor, D. Diterpene lipo-alkaloids with selective activities on cardiac $\mathrm{K}+$ channels. Planta Med. 2017, 83, 1321-1328.

[4] Guo, Q. L.; Xia, H.; Shi, G. N.; Zhang, T. T.; Shi, J. G. Aconicarmisufonine $\mathrm{A}$, a sulfonated C20-diterpenoid alkaloid from the lateral roots of Aconitum carmichaelii. Org. Lett. 2018, 20, 816-819.
[5] He, J. B.; Luan, J.; Lv, X. M.; Rui, D. Y.; Tao, J.; Wang, B.; Niu, Y. F.; $\mathrm{Ju}, \mathrm{H}$. P. Navicularines A-C: new diterpenoid alkaloids from Aconitum naviculare and their cytotoxic activities. Fitoterapia 2017, 120, 142-145.

[6] Li, X. D.; Gu, L. W.; Yang, L.; Zhang, D.; Shen, J. Y. Aconitine: a potential novel treatment for systemic lupus erythematosus. J. Pharmacol. Sci. 2017, 133, 115-121.

[7] Ahmad, H.; Ahmad, S.; Shah, S. A. A.; Latif, A.; Ali, M.; Khan, F. A.; Tahir, M. N.; Shaheen, F.; Wadood, A.; Ahmad, M. Antioxidant and anticholinesterase potential of diterpenoid alkaloids from Aconitum heterophyllum. Bioorg. Med. Chem. 2017, 25, 3368-3376.

[8] Akhtar, J.; Khan, A. A.; Ali, Z.; Haider, R.; Shahar, Y. M. Structureactivity relationship (SAR) study and design strategies of nitrogencontaining heterocyclic moieties for their anticancer activities. Eur. J. Med. Chem. 2017, 125, 143-189.

[9] Ren, M. Y.; Yu, Q. T.; Shi, C. Y.; Luo, J. B. Anticancer activities of C18-, C19-, C20-, and bis-diterpenoid alkaloids derived from genus Aconitum. Molecules 2017, 22, 267.

[10] Wada, K.; Yamashita, H. Cytotoxic effects of diterpenoid alkaloids against human cancer cells. Molecules 2019, 24, 2317.

[11] Sheng, L. R.; Xu, M.; Xu, L. Q.; Xiong, F. Cytotoxic effect of lappaconitine on non-small cell lung cancer in vitro and its molecular mechanism. J. Chin. Med. Mater. 2014, 37, 840-843.

[12] Lin, L.; Xiao, L. Y.; Lin, P. Y.; Zhang, D.; Chen, Q. W. Experimental study on the anti-tumor effect of lappaconitine hydrobromide. TCM Res. 2005, 18, 16-18.

[13] Zhao, D. K.; Shi, X. Q.; Zhang, L. M.; Yang, D. Q.; Guo, H. C.; Chen, Y. P.; Shen, Y. Four new diterpenoid alkaloids with antitumor effect from Aconitum nagarum var. heterotrichum. Chin. Chem. Lett. 2017, 28, 358-361.

[14] He, Y. Q.; Zhang, D.; West, L. M. Delphatisine D and chrysotrichumine A, two new diterpenoid alkaloids from Delphinium chrysotrichum. Fitoterapia 2019, 139, 1-4.

[15] Liang, X. X.; Chen, L.; Song, L.; Fei, W. B.; He, C. L.; Yin, Z. Q. Diterpenoid alkaloids froom the root of Aconitum sinchiangense W.T. Wang with their antitumor and antibacterial activities. Nat. Prod. Res. 2017, 31, 2016-2023.

[16] Wada, K.; Hazawa, M.; Takahashi, K. Structure-activity relationships and the cytotoxic effects of novel diterpenoid alkaloid derivatives against A549 human lung carcinoma cells. J. Nat. Med. 2011, 65, 43-49.

[17] He, J. B.; Luan, J.; Lv, X. M.; Rui, D. Y.; Tao, J.; Wang, B.; Niu, Y. F.; Ju, H. P. Navicularines A-C: new diterpenoid alkaloids from Aconitum naviculare and their cytotoxic activities. Fitoterapia 2017, 120, 142-145.

[18] Dai, S. J.; Liang, D. D.; Ren, Y.; Liu, K.; Shen, L. New neo-clerodane diterpenoid alkaloids from Scutellaria barbata with cytotoxic activities. Chem. Pharm. Bull. 2008, 56, 207-209.

[19] Dai, S. J.; Wang, G. F.; Chen, M.; Liu, K.; Shen, L. Five new neo-clerodane diterpenoid alkaloids from Scutellaria barbata with cytotoxic activities. Chem. Pharm. Bull. 2007, 55, 1218-1221.

[20] Ivanets, E. V.; Yurchenko, A. N.; Smetanina, O. F.; Rasin, A. B.; Zhuravleva, O. I.; Pivkin, M. V.; Popov, R. S.; Amsberg, G. V.; Afiyatullov, S. S.; Dyshlovoy, S. A. Asperindoles A-D and a $p$-Terphenyl derivative from the ascidian-derived fungus Aspergillus sp. KMM4676. Mar. Drugs 2018, 16, 232.

[21] Zhang, H.; Guo, Z. J.; Han, L.; You, X. J.; Xu, Y. The antitumor effect and mechanism of taipeinine $A$, a new C19-diterpenoid alkaloid from Aconitum taipeicum, an the HepG2 human hepatocellular carcinoma cell line. J. BUON 2014, 19, 705-712.

Received September 24, 2020 Accepted November 3, 202 